\title{
Childhood Bullying and Adolescent Mental Health for Sexual Minorities: Prospective evidence from a population-based birth cohort
}

\author{
Joel Mittleman, MA, MSc
}

\begin{abstract}
Affiliation: Princeton University, Office of Population Research
Address correspondence to: Joel Mittleman, Office of Population Research, Wallace Hall, Princeton University, Princeton, NJ, 08544, joeljm@princeton.edu, 610-295-7136

Funding Source: The Fragile Families and Childhood Wellbeing Study is supported by the Eunice Kennedy Shriver National Institute of Child Health and Human Development (NICHD) of the National Institutes of Health under award numbers R01HD36916, R01HD39135, and R01HD40421, as well as a consortium of private foundations. The content is solely the responsibility of the author and does not necessarily represent the official views of the National Institutes of Health.
\end{abstract}

Financial Disclosure: Joel Mittleman has no financial relationships relevant to this article to disclose.

Conflict of Interest: Joel Mittleman has no conflicts of interest to disclose.

Clinical Trial Registration: N/A

Acknowledgments Jeanne Brooks-Gunn and Sara McLanahan provided valuable feedback on an earlier draft. 
Objectives. To provide the first prospective evidence on sexual minorities' early childhood peer victimization experiences and estimate the extent to which victimization histories explain adolescent mental health disparities.

Methods. Longitudinal data from the Fragile Families and Childhood Wellbeing Study, a population-based cohort of children born in twenty American cities between 1998 and 2000 , were used. Multivariate regression analyses examined peer victimization at ages 5, 9 and 15 and anxiety/depression at 15 . Teens reported sexual minority status during interviews conducted between 2014 and 2017.

Results. Compared to their peers, sexual minorities experienced similar rates of victimization at age 5 but higher rates ages 9 and 15 . Over and above current bullying, prior victimization predicted worse outcomes on three clinically validated diagnostic scales for anxiety/depression. Results were consistent using parent and child reports. Despite sexual minorities' elevated rates of bullying, only about $20 \%$ of their mental health disparities were explained by peer victimization.

Conclusions. Sexual minorities' bullying risk begins years earlier than previously documented and persists into adolescence. Victimization prevalence estimates based on adolescents' recent experiences will substantially underestimate lifetime exposure to victimization. 
Although most lesbian, gay and bisexual youth are resilient in the face of structural and interpersonal stressors, sexual minority teens nevertheless report higher rates of depressive and anxious symptoms than their peers. ${ }^{1}$ Recent nationally representative data illustrate the challenges that contemporary sexual minority teens face. Of the approximately 1.3 million American high school students identifying as lesbian, gay or bisexual in the 2015 national Youth Risk Behavior Survey, 43\% reported having "seriously considered" suicide, compared to $15 \%$ of straight students. ${ }^{2}$ Other populationbased studies confirm these disparities, with one meta-analysis estimating that sexual minority youth had 194\% greater odds of reporting depressive symptoms. ${ }^{3}$ With suicide having recently become the second leading cause of death among American adolescents, understanding the social determinants of mental health for vulnerable teens is an important public health priority. ${ }^{4}$

One key factor shaping sexual minorities' mental health is their exposure to peer victimization. Research consistently documents that sexual minority teens report higher rates of bullying: one recent review found that sexual minorities had $168 \%$ greater odds of being assaulted by peers and $285 \%$ greater odds of skipping school out of fear. ${ }^{5}$ Given the impact of bullying on child and adolescent health ${ }^{6-9}$ several studies have found that peer victimization partially explains the mental health disparities reported between sexual minorities and their peers. ${ }^{10-12 .}$

Despite numerous studies documenting sexual minorities' experiences with bullying, almost all of the existing evidence is based on cross-sectional surveys administered to students in middle or high schools. For example, every one of the 27 studies included in a recent meta-analysis used cross-sectional samples drawn from teens 
in grades 9-12 or ages 14-19. ${ }^{5}$ There is little longitudinal evidence on how sexual minorities' victimization experiences change over time and no prospective evidence on the onset of bullying risk in early childhood. Two recent studies find that youth who later report sexual minority status already reported higher rates of bullying in the first wave of each study: at average ages of $11^{13}$ and $13,{ }^{10}$ respectively. However, there is reason to hypothesize that sexual minority children's trajectories of bullying exposure begin much earlier. Childhood gender nonconformity—which is common among sexual minority youth $^{14,15}$ and itself an important risk factor for bullying ${ }^{15,16}$ - has been found to be already observable by age five. ${ }^{15}$

Given evidence suggesting that children begin exhibiting bullying behaviors already in preschool, ${ }^{17}$ it is possible that sexual minorities face higher rates of bullying from the first time they enter school. If this is true, then research assessing bullying only at older ages may substantially underestimate the full extent of victimization endured by sexual minorities. Because chronic bullying appears to be uniquely consequential in shaping health outcomes, ${ }^{18,19}$ it is important to understand both the onset and the trajectory of bullying risk among sexual minority youth.

The current study addresses these issues, using newly collected data on to provide the first prospective, population-based evidence on sexual minorities' bullying risk from early childhood through adolescence. After documenting sexual minorities' peer victimization at ages 5,9 and 15 , this study estimates the extent to which victimization histories explain current disparities on three clinically validated scales of adolescent anxiety and depression. Where possible, key results are replicated using reports from both children and their parents, providing robust evidence of the underlying phenomena. 


\section{METHOD}

\section{Sample}

The Fragile Families and Childhood Wellbeing Study (FFCWS) is a stratified, multistage probability sample of 4,892 children born in twenty American cities between 1998 and $2000 .{ }^{20}$ Sampling cities, then hospitals, then births, the weighted FFCWS sample is representative of all births during that period in American cities with populations of 200,000 or more. With its urban sampling frame and oversample of nonmarital births, the FFCWS is disproportionately constituted by children of color, providing a valuable complement to data sources on sexual minority youth that include primarily white samples. $^{11,21}$

Following postpartum interviews with the child's biological mother and father, the FFCWS has conducted five additional waves of data collection, documenting child and family development approximately one, three, five, nine and fifteen years after the child's birth. The latest wave of data collection was conducted between February 2014 and March 2017, during which time teens were an average of 15.6 years old (minimum = 14.4 , maximum $=18.8$ ). Year 15 parent and teen interviews were conducted separately, primarily by phone ( $94 \%$ and $95 \%$ of teen and parent interviews, respectively), with almost all of the remaining interviews conducted in person. One teen interview and nine parent interviews were administered as online surveys.

At Year 15, there were 3,429 cases in which both teens and their primary caregiver completed interviews. Of these cases, the current study excluded: those who were homeschooled and therefore not asked about in-school bullying $(n=62)$; those with missing information on same-sex attraction $(n=26)$ or adolescent bullying $(n=11)$; and 
those teens who displayed a pattern of improbable responses $(n=2)$. To simplify the comparison group, all analyses presented also exclude teens who report having never felt attraction to someone from either sex $(n=306)$, yielding a final analytic sample of 3,022 cases. Cases with missing data in previous survey waves were retained by implementing multiple imputation by chained equations; all covariates in this study were included in the imputation equations. ${ }^{22}$ Results using only unimputed complete cases are included in Supplementary Tables 1 and 2; all results are substantively similar.

\section{Measures}

Same-Sex Attraction

Consistent with best practice recommendations for assessing sexual orientation in surveys of adolescents, ${ }^{3,23}$ sexual minority status was characterized using reports of same-sex attraction. After being told "now we would like to talk about your experience with romantic relationships," all teens were asked "Have you ever liked a girl as more than just a friend?" and "Have you ever liked a boy as more than just a friend?" The Year 15 interview did not collect a measure of gender identity and so sex at birth was used to determine reports of same-sex attraction.

\section{Peer Victimization}

Peer victimization was reported by parents at ages 5 and 9 and by children at 9 and 15 . Parents were asked whether the child "gets teased a lot," with response options of "not true," "somewhat or sometimes true," and "very true or often true." Because few parents reported that the statement was "very" true ( $\sim 2 \%$ of responses), a dichotomized measure of not true (0) versus at least somewhat true (1) was constructed. Children were asked 
four questions about peer victimization: how often, in the last month, they had had other kids "pick on you or say mean things you," "hit you or threaten to hurt you physically," "take your things, like your money or lunch, without asking," and "purposely leave you out of activities." Children were given five response options, ranging from "never" to "every day." Because sexual minorities experienced higher rates of every victimization type and all types were highly correlated ( $\alpha=0.66$ at $9 ; \alpha=0.60$ at 15$)$, a summary measure of bullying frequency was constructed: whether the child reported experiencing one or more forms of bullying at least once, at least weekly, and daily. To avoid collinearity when victimization frequency was used to predict adolescent mental health, the above measures were reconstructed to produce mutually exclusive indicators: any (but less than weekly) bullying, weekly (but less than daily) bullying, and daily bullying.

\section{Adolescent Mental Health}

The current study examined reports on three validated scales of adolescent mental health: the Center for Epidemiologic Studies Depression Scale (CES-D) ${ }^{24}$ the Brief Symptom Inventory 18 (BSI 18) Anxiety Scale, ${ }^{25}$ and the Internalizing Problems Scale of Achenbach's Child Behavior Checklist (CBCL/6-18) ${ }^{26}$ The CES-D and BSI 18 were reported by teens, describing the four weeks prior to their interview; the CBCL/6-18 was reported by parents, describing the teen generally. The CES-D included five items $(\alpha=0.76)$ - "I feel I cannot shake off the blues, even with the help from my family and my friends," "I feel sad," "I feel happy (reversed)," "I feel life is not worth living," and "I feel depressed" - and the BSI 18 Anxiety Scale included six items ( $\alpha=0.76)$ - "I have spells of terror or panic," "I feel tense or keyed up," "I get suddenly scared for no reason," "I feel nervous or shaky inside," "I feel fearful," and "I feel so restless I can't sit 
still." The CBCL/6-18 included eight items $(\alpha=0.79)$, describing whether the teen: "cries a lot," "feels worthless or inferior," "is nervous, high-strung, or tense," "is too fearful or anxious," "feels too guilty," "worries," "is underactive, slow moving, or lacks energy," and "is unhappy, sad or depressed." Responses on the CES-D and BSI 18 were scored from 0 ("strongly disagree") to 3 ("strongly agree"); CBCL-6/18 responses were scored from 0 ("not true") to 2 ("often true"). Scales were constructed by calculating mean responses across items, with higher values indicating greater symptomatology.

\section{Covariates}

To better assess the risks uniquely associated with sexual minority status, all multivariate analyses adjusted for six child background characteristics and three known risk factors for bullying victimization. Background characteristics were: sex at birth, race/ethnicity, parent nativity, mother's marital status and educational attainment at the time of the birth, and the child's age at the time of the relevant interview. Bullying risk factors were: whether the child has a food allergy or physical disability (both reported by parents at 5 ,

9 and 15) and whether the child's BMI qualifies them as obese. BMI was calculated using in-person measurements at 5 and 9 and self-reported measurements at 15 . All analyses of Year 9 and 15 outcomes also controlled for the child's pubertal development at the time of the age nine interview. Pubertal development was measured using the average of parents' reports on five sex-specific items assessing whether physical developments have not started (1), barely started (2), definitely started (3), or are complete (4).

\section{Statistical Analyses}

Data were processed and analyzed in Stata 14.0 (Stata Corp, College Station, TX) using procedures to pool results across 20 imputed datasets. After presenting summary statistics 
on the analytic sample, two sets of ordinary least squares regression analyses are presented. All analyses are descriptive and cannot support claims about the direction of causality in any estimated relationship. P-values were calculated using two-tailed tests; all "significant" results described in the text reflect p-values less than 0.05 .

\section{RESULTS}

\section{Sample Description}

Information on the analytic sample is included in Table 1. About $11 \%$ of the sample reported same-sex attraction. Teens who reported same-sex attraction were significantly different from teens who reported only other-sex attraction across four background characteristics: they were more likely to be female, to have native born parents, to have parents unmarried at baseline and to be slightly more advanced in their pubertal development by age nine. Apart from the sex difference in sexual minority reporting rates - a pattern replicated in recent adolescent ${ }^{2}$ and adult ${ }^{27}$ samples - all of these differences are small. In terms of bullying risk factors, the only significant difference observed is that sexual minorities had higher obesity rates at ages 9 (30.6\% vs. $24.9 \%)$ and $15(24.3 \%$ vs. $19.6 \%)$. These elevated obesity rates from age 9 onward are themselves a public health concern and may be a response to peer victimization and minority stress more broadly.

\section{Differences in Peer Victimization Histories and Adolescent Mental Health}

Table 2 presents regression-adjusted victimization rates and adolescent mental health outcomes for sexual minorities and their peers. Observed rates, presented in Supplementary Table 3, are substantively identical. 
Contrary to expectations, there were no significant differences in parent reports of their child being "teased a lot" at age five. Sexual minorities had a slightly elevated risk for early childhood teasing — $14 \%$ vs. $12 \%$ — but this difference was not significantly different than zero. By age nine, however, reports on the same question had diverged substantially. Between five and nine, the parents of non-sexual minority children reported only a slight increase in teasing: from $12 \%$ to $15 \%$. For sexual minorities, however, teasing nearly doubled: increasing from $14 \%$ to $26 \%$. Already at age nine-when most of these children were in third grade — the parents of sexual minorities were $76 \%$ more likely to report that their child was "teased a lot."

The children themselves confirm these experiences. When asked how "kids in their school and neighborhood" had treated them in the past month, nine year olds who would later report same-sex attraction were $17 \%$ more likely to report having faced any form of victimization. The disparity between sexual minorities and their peers was greater for reports of more frequent victimization. Compared to their peers, sexual minorities were $31 \%$ more likely to report weekly bullying and $67 \%$ more likely to report daily bullying. Nearly one in four children (23\%) who later reported same-sex attraction reported being bullied every day in the month prior to their Year 9 interview.

Consistent with prior research, ${ }^{6}$ bullying rates had fallen by age fifteen. Nevertheless, sexual minority youth continued to experience higher levels of victimization than their peers. Indeed, although the level of bullying experienced by sexual minorities fell between nine and fifteen, the disparity between them and their peers increased. Compared to their peers, sexual minority teens were $58 \%$ more likely to report any bullying, $91 \%$ more likely to report weekly bullying, and $266 \%$ more likely to 
report daily bullying.

Marked disparities were also reported for mental health outcomes. Both the teens themselves and their parents reported that sexual minorities experienced significantly greater levels of depressive and anxious symptoms. Notably, however, even though sexual minorities scored higher on every scale, the scores themselves still indicate that sexual minorities generally disagreed with the underlying diagnostic items.

To provide a more intuitive metric for interpreting these scores, Table 2 presents parents' reports of whether the teen had ever been professionally diagnosed with depression or anxiety as well as whether the teen was currently taking prescription medication to address depression/anxiety. Although these outcomes reflect teens' health care access and utilization in addition to their underlying symptoms, these measures are consistent with the reports on the diagnostic scales in suggesting two key facts. First, in absolute terms, most sexual minorities in this sample did not experience clinically significant levels of depression or anxiety: $23 \%$ had been diagnosed and $10 \%$ were taking medication. Nevertheless, compared to their peers, sexual minorities experienced substantially greater rates of these outcomes: they were roughly twice as likely to have received a diagnosis and to be currently taking a prescription medication.

\section{Explaining Mental Health Disparities}

Can sexual minorities' histories of bullying explain the mental health disparities between them and their peers? Table 3 presents the results of analyses exploring this question. To keep units consistent across the three scales being analyzed, scores were standardized to a mean of zero and standard deviation of one. The results in Table 3 provide mixed evidence with respect to the role that peer victimization plays in shaping 
mental health disparities.

On the one hand, these results provide several indications that bullying is a robust predictor of depressive and anxious symptomology. Even controlling for current victimization, teens with histories of victimization experienced significantly worse depression/anxiety. Indeed, for two out of the three outcomes, teasing reported ten years earlier — when children were only five — significantly predicted adolescent mental health. Additionally, there appears to be a dose effect associated with bullying, especially at fifteen: teens bullied daily experience worse outcomes than those bullied weekly, who in turn experience worse outcomes than those bullied less than weekly. Finally, it is notable that both of these patterns are consistent across parent and teen reports, increasing confidence in the underlying phenomena and relationships.

On the other hand, despite the significance of peer victimization in predicting adolescent mental health generally, victimization histories explain relatively little of the mental health disparities between sexual minorities and their peers. Again, results are fairly consistent across outcomes: accounting for victimization explains about $22 \%$ of the disparity in both parents' reports of internalizing problems and teens' reports of anxiety. For teens' reports of depression, where the initial disparity is largest, victimization explains only about $17 \%$ of the disparity. Despite some suggestive evidence, tests generally failed to detect any significant interaction between sexual minority status and victimization. That is, although sexual minorities experienced higher levels of bullying, any given level of bullying does not appear to have been more (or less) consequential in shaping their mental health than it was for their peers. Even accounting for teens' peer victimization histories dating back to the time of school entry, large mental health 
disparities remain unexplained.

\section{DISCUSSION}

The current study's results build upon existing research to advance our understanding of sexual minority youth in a few significant ways.

First, this study suggests that the measures of peer victimization most commonly available to researchers - measures of recent bullying reported by adolescents — are likely to substantially understate the full extent of victimization that sexual minority teens have previously endured. In this geographically diverse, contemporary cohort, $60 \%$ of sexual minority teenagers reported not facing any peer victimization in the last month. Looking back in these teens' lives, however, reveals that the majority still had histories of prior victimization. Among those sexual minorities who were not bullied at age fifteen, $66 \%$ reported facing at least some bullying at age nine. Indeed, when they were nine, $17 \%$ of non-bullied sexual minority teens reported being bullied every day.

By documenting sexual minorities' elevated rates of bullying already at age nine, the current study joins two previous studies in finding that children who later reported sexual minority status began being bullied at ages when few would have been able to self-identify as LGB. ${ }^{10,13}$ This study updates prior findings using a contemporary cohort and extends them two years earlier in children's lives. Notably, at just nine years old, few of these children had begun to show any sign of pubertal development.

At the same time, the current study provides suggestive evidence that peer rejection was not always part of these children's lives: at age five, parents reported that sexual minorities were teased in much the same way as their peers. The dramatic change in parent reports between ages five and nine suggests that the early elementary grades 
may be a critical time to intervene to prevent the emergence of bullying behaviors. It also suggests that those years may mark a developmentally significant time for sexual minority youth in ways that merit further study.

Sexual minority teens' long histories of peer victimization help to explain the substantial mental health disparities between them and their peers. Unusual among studies of sexual minority teens, the current study was able use reports from parents in addition to teen self-reports. Across parent and teen reported measures, early victimization predicted levels of anxiety and depression over and above those predicted by recent experiences. Even so, much of the mental health disparities experienced by sexual minorities persisted even after accounting for victimization history. This result is consistent with prior research showing that peer victimization alone cannot account for the mental health challenges that sexual minority teens endure. ${ }^{10-12}$ The consistency of these results underscores the importance of multi-pronged research and policy agenda, addressing both the interpersonal and the structural factors that shape the mental health outcomes of sexual minority youth.

\section{Limitations}

These results should be considered in light of the limitations that this study faced. First, although the FFCWS sample is more geographically diverse than some prior studies of sexual minority bullying, ${ }^{13,28}$ it only includes children who were born in large American cities. Because of this, this study's results cannot be assumed to be representative of all children nationwide. Second, the gaps in FFCWS data collection between ages five, nine and fifteen mean that this study likely misses key moments in sexual minorities' bullying trajectories. For example, interviews during middle school 
would have likely revealed a particularly acute period of victimization. Third, although supplementary analyses found no consistent evidence that results were moderated by sex at birth, the limited numbers of same-sex attracted boys in the FFCWS prevented any clear inferences about sex-specific patterns of victimization and mental health. Finally, although sexual minorities' heightened risk for bullying already by age nine suggests an important role for childhood gender nonconformity, the FFCWS lacks any direct reports of "masculine" or "feminine" dress, speech, interests, or comportment.

\section{Public Health Implications}

Despite these limitations, this study has important implications for public health research and practice. First, this study's results suggest that public health researchers and professionals should assess not only current experiences of bullying, but also lifelong histories of victimization. Second, these results underscore the importance of intervening early to prevent the emergence of bullying behaviors among young children. Finally, this study illustrates both the importance and limitations of bullying prevention as a strategy for addressing sexual minority health disparities. School-based interventions, without broader changes in the social and legal environment where children grow up, are unlikely to fully address "the elusive promise of LGBT equality." 29 


\section{REFERENCES}

1. National Academies of Sciences, Engineering, and Medicine. The Health of Lesbian, Gay, Bisexual, and Transgender People: Building a Foundation for Better Understanding. Washington, DC: The National Academies Press; 2011

2. Kann L, Olsen EOM, McManus T, et al. Sexual identity, sex of sexual contacts, and health-related behaviors among students in grades 9-12 - United States and selected sites, 2015. MMWR Surveill Summ. 2016;65(9):1-202

3. Lucassen M, Stasiak K, Samra R, et al. Sexual minority youth and depressive symptoms or depressive disorder: A systematic review and meta-analysis of population-based studies. Aust N Z J Psychiatry 2017; 51(8):774-787

4. Population Reference Bureau. Suicide Replaces Homicide as Second-Leading Cause of Death Among U.S. Teenagers. Washington, DC: Author; 2016.

5. Friedman MS, Marshal MP, Guadamuz TE, et al. A Meta-Analysis of Disparities in Childhood Sexual Abuse, Parental Physical Abuse, and Peer Victimization Among Sexual Minority and Sexual Nonminority Individuals. Am J Public Health 2011; 101(8):1481-1498.

6. National Academies of Sciences, Engineering, and Medicine. Preventing Bullying Through Science, Policy, and Practice. Washington, DC: The National Academies Press; 2016

7. American Public Health Association. A Public Health Approach to Bullying Prevention. Washington, DC: Author; 2014

8. Joint AACAP and APA position statement on prevention of bullying-related morbidity and mortality. Washington, DC: American Psychiatric Association. 2011

9. Singham T, Viding E, Schoeler T, et al. Concurrent and longitudinal contribution of exposure to bullying in childhood to mental health: the role of vulnerability and resilience. JAMA Psychiatry. 2017;74(11): 1112-1119.

10. Robinson JP, Espelage DL, Rivers I. Developmental trends in peer victimization and emotional distress in LGB and heterosexual youth. Pediatrics. 2013;131(3):423-430.

11. Robinson JP and Espelage DL. Bullying Explains Only Part of LGBTQHeterosexual Risk Disparities: Implications for Policy and Practice. Educ Res. 2012;41(8):309-319.

12. Birkett M, Espelage DL, Koenig B. LGB and questioning students in schools: the moderating effects of homophobic bullying and school climate on negative outcomes. J Youth Adolesc. 2009;38(7):989-1000.

13. Schuster MA, Bogart LM, Elliott MN, et al. A longitudinal study of bullying of sexual-minority youth. $N$ Engl J Med. 2015;372(19):1872-1874

14. Bailey JM, Zucker KJ. Childhood sex-typed behavior and sexual orientation: a conceptual analysis and quantitative review. Dev Psychol. 1995;31(1):43-55.

15. Rieger G, Linsenmeier JA, Gygax L, Bailey JM. Sexual orientation and childhood gender nonconformity: evidence from home videos. Dev Psychol. 2008;44(1):46-58.

16. Roberts AL, Rosario M, Slopen N, Calzo JP, Austin SB. Childhood gender nonconformity, bullying victimization, and depressive symptoms across 
adolescence and early adulthood: an 11-year longitudinal study. $J$ Am Acad Child Adolesc Psychiatry. 2013;52(2):143-52.

17. Halpern J, Jutte D, Colby J, Boyce WT. Social dominance, school bullying, and child health: what are our ethical obligations to the very young? Pediatrics. 2015; 135: S24-S30.

18. Bogart LM, Elliott MN, et al. Peer victimization in fifth grade and health in tenth grade. Pediatrics. 2014;133(2):440-447

19. Mustanski B, Andrews R, Puckett JA. The effects of cumulative victimization on mental health among lesbian, gay, bisexual, and transgender adolescents and young adults. Am J Public Health. 2016;106(3):527-533

20. Reichman NE, Teitler JO, Garfinkel I, McLanahan S. Fragile families: sample and design. Children and Youth Services Review. 2001;23(4/5):303-326

21. Kosciw JG, Greytak EA, Giga NM, et al. The 2015 National School Climate Survey: The experiences of lesbian, gay, bisexual, transgender, and queer youth in our nation's schools. New York, NY: GLSEN; 2016.

22. White IR, Royston P, Wood AM. Multiple imputation using chained equations: issues and guidance for practice. Stat Med. 2011;30(4):377-399

23. The Williams Institute. Best Practices for Asking Questions about Sexual Orientation on Surveys. Los Angeles, CA: Author; 2009

24. Radloff LS. The use of the Center for Epidemiologic Studies Depression Scale in adolescents and young adults. $J$ Youth Adolesc. 1991;20(2):149-166.

25. Derogatis LR and Savitz KL. The SCL-90-R and Brief Symptom Inventory (BSI) in primary care. In Maruish ME (Ed), (2000). Handbook of psychological assessment in primary care settings. Mahwah, NJ, US: Lawrence Erlbaum Associates Publishers; 297-334.

26. Nakamura BJ, Ebesutani C, Bernstein, A and Chorpita BF. A psychometric analysis of the Child Behavior Checklist DSM-oriented scales. J Psychopathol Behav Assess. 2009;31(3):178-189.

27. England P, Mishel E, Caudillo ML. Increases in sex with same-sex partners and bisexual identity across cohorts of women (but not men). Sociological Science. 2016;3:951-970.

28. Russell ST, Everett BG, Rosario M, Birkett M. Indicators of victimization and sexual orientation among adolescents: analyses from Youth Risk Behavior Surveys. Am J Public Health. 2014;104(2):255-261

29. Meyer IH. The elusive promise of LGBT equality. Am J Public Health. 2016;106(8): 1356-1358. 
TABLE 1 Description of Youth in Analytic Sample: Fragile Families \& Childhood Wellbeing Study, United States, $1998-2000$ to $2014-2017$

\begin{tabular}{|c|c|c|c|}
\hline & $\begin{array}{c}\text { Same-Sex Attraction } \\
(\mathrm{N}=326), \\
\% \text { or Mean }\end{array}$ & $\begin{array}{c}\text { Only Other-Sex Attraction } \\
(\mathrm{N}=2,696), \\
\% \text { or Mean }\end{array}$ & $P$ \\
\hline Male & $18.7^{* \star *}$ & 56.4 & $<0.00$ \\
\hline Black & 51.8 & 49.2 & 0.37 \\
\hline Hispanic & 22.4 & 25.6 & 0.21 \\
\hline White & 18.7 & 17.6 & 0.63 \\
\hline Either Parent Immigrant & $11.3^{*}$ & 16.7 & 0.01 \\
\hline Mother College Graduate at Birth & 8.9 & 11.0 & 0.25 \\
\hline Parents Married at Birth & $16.6^{* *}$ & 23.7 & $<0.00$ \\
\hline Pubertal Development Scale: Year 9 & $1.6^{* * *}$ & 1.5 & $<0.00$ \\
\hline \multicolumn{4}{|l|}{ Child's Age } \\
\hline Year 5 & 5.4 & 5.4 & 0.99 \\
\hline Year 9 & 9.3 & 9.3 & 0.55 \\
\hline Year 15 & 15.7 & 15.6 & 0.13 \\
\hline \multicolumn{4}{|l|}{ Food Allergy } \\
\hline Year 5 & 3.8 & 3.1 & 0.55 \\
\hline Year 9 & 4.1 & 4.3 & 0.89 \\
\hline Year 15 & 4.9 & 4.7 & 0.90 \\
\hline \multicolumn{4}{|l|}{ BMI: Obese } \\
\hline Year 5 & 19.0 & 18.0 & 0.72 \\
\hline Year 9 & $31.1^{*}$ & 25.1 & 0.03 \\
\hline Year 15 & $24.3^{*}$ & 19.5 & 0.05 \\
\hline \multicolumn{4}{|l|}{ Physical Disability (e.g., Asthma) } \\
\hline Year 5 & 22.3 & 22.9 & 0.83 \\
\hline Year 9 & 23.6 & 27.4 & 0.15 \\
\hline Year 15 & 29.8 & 32.5 & 0.32 \\
\hline
\end{tabular}


TABLE 2 Peer Victimization and Adolescent Mental Health, Levels and Disparities: Fragile Families \& Childhood Wellbeing Study, United States, 1998-2000 to 2014-2017

\begin{tabular}{|c|c|c|c|c|}
\hline & $\begin{array}{l}\text { Same-Sex } \\
\text { Attraction } \\
(\mathrm{N}=334) \text {, } \\
\% \text { or mean }\end{array}$ & $\begin{array}{c}\text { Only Other-Sex } \\
\text { Attraction } \\
(\mathrm{N}=2,701) \\
\% \text { or mean }\end{array}$ & $\begin{array}{c}\text { Relative } \\
\text { Risk Ratio }\end{array}$ & $P$ \\
\hline \multicolumn{5}{|l|}{ Bullying Rates } \\
\hline \multicolumn{5}{|l|}{ Parent Reports } \\
\hline Year 5: Child gets teased a lot & 14.0 & 12.1 & 1.16 & 0.52 \\
\hline Year 9: Child gets teased a lot & $26.2^{* * *}$ & 14.9 & 1.76 & $<0.00$ \\
\hline \multicolumn{5}{|l|}{$\underline{\text { Child Reports }}$} \\
\hline \multicolumn{5}{|l|}{ Year 9: } \\
\hline Any Bullying & $67.4^{* \star *}$ & 57.6 & 1.17 & $<0.00$ \\
\hline Bullying At Least Weekly & $48.0^{* * *}$ & 37.1 & 1.29 & $<0.00$ \\
\hline Daily Bullying & $23.4^{* * *}$ & 14.2 & 1.65 & $<0.00$ \\
\hline \multicolumn{5}{|l|}{ Year 15: } \\
\hline Any Bullying & $40.2^{* \star *}$ & 25.4 & 1.58 & $<0.00$ \\
\hline Bullying At Least Weekly & $24.5^{* * *}$ & 12.8 & 1.91 & $<0.00$ \\
\hline Daily Bullying & $6.6^{* * *}$ & 1.8 & 3.66 & $<0.00$ \\
\hline \multicolumn{5}{|l|}{ Adolescent Mental Health } \\
\hline \multicolumn{5}{|l|}{ Parent Reports } \\
\hline Internalizing Scale [0 - 2] & $0.38^{* * *}$ & 0.28 & & $<0.00$ \\
\hline Diagnosed with Anxiety/Depression & $23.2^{* \star *}$ & 14.9 & 1.98 & $<0.00$ \\
\hline Taking Anxiety/Depression Med & $10.0^{* * *}$ & 4.4 & 2.27 & $<0.00$ \\
\hline \multicolumn{5}{|l|}{ Teen Reports } \\
\hline Anxiety Scale [0 - 3] & $1.2^{\star \star *}$ & 0.8 & & $<0.00$ \\
\hline Depression Scale [0 - 3] & $1.1^{* \star *}$ & 0.6 & & $<0.00$ \\
\hline
\end{tabular}


TABLE 3 Explaining Sexual Minority Mental Health Disparities: Fragile Families \& Childhood Wellbeing Study, United States, $1998-2000$ to $2014-2017$

\begin{tabular}{|c|c|c|c|c|c|c|}
\hline \multirow{2}{*}{$\begin{array}{l}\text { Same-Sex Attracted } \\
\text { (Ref: Only Other-Sex } \\
\text { Attracted) }\end{array}$} & \multicolumn{2}{|c|}{$\begin{array}{c}\text { Parent Report: } \\
\text { Internalizing Problems }\end{array}$} & \multicolumn{2}{|c|}{$\begin{array}{l}\text { Teen Report: } \\
\text { Anxiety }\end{array}$} & \multicolumn{2}{|c|}{$\begin{array}{l}\text { Teen Report: } \\
\text { Depression }\end{array}$} \\
\hline & $\begin{array}{c}0.36^{* * *} \\
{[0.24,0.48]}\end{array}$ & $\begin{array}{c}0.28^{* * *} \\
{[0.16,0.39]}\end{array}$ & $\begin{array}{c}0.54^{* * *} \\
{[0.42,0.66]}\end{array}$ & $\begin{array}{c}0.42^{* * *} \\
{[0.30,0.54]}\end{array}$ & $\begin{array}{c}0.68^{* * *} \\
{[0.57,0.80]}\end{array}$ & $\begin{array}{c}0.57^{* * *} \\
{[0.46,0.68]}\end{array}$ \\
\hline \multicolumn{7}{|l|}{ Year 15 Bullying: } \\
\hline Less than Weekly & & $\begin{array}{c}0.15^{*} \\
{[0.03,0.26]}\end{array}$ & & $\begin{array}{c}0.29^{* * *} \\
{[0.18,0.41]}\end{array}$ & & $\begin{array}{c}0.37^{* * *} \\
{[0.26,0.48]}\end{array}$ \\
\hline Weekly Bullying & & $\begin{array}{c}0.29^{* * *} \\
{[0.19,0.40]}\end{array}$ & & $\begin{array}{c}0.59^{* * *} \\
{[0.48,0.70]}\end{array}$ & & $\begin{array}{c}0.62^{* * *} \\
{[0.52,0.72]}\end{array}$ \\
\hline Daily Bullying & & $\begin{array}{c}0.50^{\star * *} \\
{[0.28,0.72]}\end{array}$ & & $\begin{array}{c}0.89 * * * \\
{[0.68,1.11]}\end{array}$ & & $\begin{array}{c}0.94^{* * *} \\
{[0.73,1.15]}\end{array}$ \\
\hline \multicolumn{7}{|l|}{ Year 9 Bullying: } \\
\hline Less than Weekly & & $\begin{array}{c}0.04 \\
{[-0.05,0.14]}\end{array}$ & & $\begin{array}{c}0.07 \\
{[-0.03,0.16]}\end{array}$ & & $\begin{array}{c}-0.00 \\
{[-0.09,0.09]}\end{array}$ \\
\hline Weekly Bullying & & $\begin{array}{c}0.19 * * * \\
{[0.09,0.29]}\end{array}$ & & $\begin{array}{c}0.08 \\
{[-0.02,0.18]}\end{array}$ & & $\begin{array}{c}0.08 \\
{[-0.02,0.17]}\end{array}$ \\
\hline Daily Bullying & & $\begin{array}{c}0.28^{* * *} \\
{[0.16,0.40]}\end{array}$ & & $\begin{array}{c}0.23^{* * *} \\
{[0.12,0.35]}\end{array}$ & & $\begin{array}{c}0.14^{*} \\
{[0.02,0.25]}\end{array}$ \\
\hline$\frac{\text { Year 5: }}{\text { Teased A Lot }}$ & & $\begin{array}{c}0.21^{* * *} \\
{[0.11,0.31]}\end{array}$ & & $\begin{array}{c}0.13^{*} \\
{[0.02,0.24]}\end{array}$ & & $\begin{array}{c}0.09 \\
{[-0.02,0.20]}\end{array}$ \\
\hline Constant & $\begin{array}{c}0.08 \\
{[-0.06,0.22]}\end{array}$ & $\begin{array}{c}-0.09 \\
{[-0.24,0.06]}\end{array}$ & $\begin{array}{c}0.02 \\
{[-0.13,0.16]}\end{array}$ & $\begin{array}{c}-0.18^{*} \\
{[-0.33,-0.03]}\end{array}$ & $\begin{array}{c}0.09 \\
{[-0.06,0.23]}\end{array}$ & $\begin{array}{c}-0.09 \\
{[-0.23,0.06]}\end{array}$ \\
\hline
\end{tabular}

Note. ${ }^{* * *} p<0.001,{ }^{* *} p<0.01,{ }^{*} p<0.05 .95 \%$ confidence intervals in brackets. Estimates produced by ordinary least squares regressions also controlling for sex at birth, race/ethnicity, parent nativity, mother's education and marital status at time of child's birth, child's age at Year 15 (mean centered), child's pubertal

development at Year 9 (mean centered), and whether, at Year 15, the child had a food allergy, a BMI qualifying them as obese, and/or a physical disability. 
SUPPLEMENTARY TABLES 
SUPPLEMENTARY TABLE 1 Results Using Unimputed Complete Cases: Peer Victimization and Adolescent Mental Health, Levels and Disparities: Fragile Families \& Childhood Wellbeing Study, United States, $1998-2000$ to $2014-2017$

\begin{tabular}{|c|c|c|c|c|}
\hline & $\begin{array}{l}\text { Same-Sex } \\
\text { Attraction } \\
(\mathrm{N}=155), \\
\% \text { or mean }\end{array}$ & $\begin{array}{c}\text { Only Other-Sex } \\
\text { Attraction } \\
(\mathrm{N}=1,255) \\
\% \text { or mean }\end{array}$ & $\begin{array}{c}\text { Relative } \\
\text { Risk Ratio }\end{array}$ & $P$ \\
\hline \multicolumn{5}{|l|}{ Bullying Rates } \\
\hline \multicolumn{5}{|l|}{$\underline{\text { Parent Reports }}$} \\
\hline Year 5: Child gets teased a lot & 9.4 & 8.9 & 1.06 & 0.88 \\
\hline Year 9: Child gets teased a lot & $29.5^{\star \star}$ & 17 & 1.74 & $<0.00$ \\
\hline \multicolumn{5}{|l|}{ Child Reports } \\
\hline \multicolumn{5}{|l|}{ Year 9: } \\
\hline Any Bullying & 70.8 & 64.1 & 1.10 & 0.11 \\
\hline Bullying At Least Weekly & $55.7^{\star \star}$ & 43.3 & 1.29 & $<0.00$ \\
\hline Daily Bullying & $26.0^{* * *}$ & 14.8 & 1.76 & $<0.00$ \\
\hline \multicolumn{5}{|l|}{ Year 15: } \\
\hline Any Bullying & $47.9^{* \star *}$ & 30.1 & 1.59 & $<0.00$ \\
\hline Bullying At Least Weekly & $29.9^{* * *}$ & 15.6 & 1.92 & $<0.00$ \\
\hline Daily Bullying & $9.1^{* * *}$ & 3.4 & 2.68 & $<0.00$ \\
\hline \multicolumn{5}{|l|}{ Adolescent Mental Health } \\
\hline \multicolumn{5}{|l|}{ Parent Reports } \\
\hline Internalizing Scale [0 - 2] & $0.41^{* * *}$ & 0.31 & & $<0.00$ \\
\hline Diagnosed with Anxiety/Depression & $27.3^{* * *}$ & 15.2 & 1.80 & $<0.00$ \\
\hline Taking Anxiety/Depression Med & $14.4^{* * *}$ & 9.1 & 1.58 & $<0.00$ \\
\hline \multicolumn{5}{|l|}{ Teen Reports } \\
\hline Anxiety Scale [0 - 3] & $1.23^{* * *}$ & 0.87 & & $<0.00$ \\
\hline Depression Scale [0 - 3] & $1.05^{\star * *}$ & 0.68 & & $<0.00$ \\
\hline
\end{tabular}


SUPPLEMENTARY TABLE 2 Results Using Unimputed Complete Cases: Explaining Sexual Minority Mental Health Disparities: Fragile Families \& Childhood Wellbeing Study, United States, 1998-2000 to 2014-2017

\begin{tabular}{|c|c|c|c|c|c|c|}
\hline \multirow{2}{*}{$\begin{array}{l}\text { Same-Sex Attracted } \\
\text { (Ref: Only Other-Sex } \\
\text { Attracted) }\end{array}$} & \multicolumn{2}{|c|}{$\begin{array}{c}\text { Parent Report: } \\
\text { Internalizing Problems }\end{array}$} & \multicolumn{2}{|c|}{$\begin{array}{l}\text { Teen Report: } \\
\text { Anxiety }\end{array}$} & \multicolumn{2}{|c|}{$\begin{array}{l}\text { Teen Report: } \\
\text { Depression }\end{array}$} \\
\hline & $\begin{array}{c}0.33^{* * *} \\
{[0.16,0.50]}\end{array}$ & $\begin{array}{c}0.24^{* * *} \\
{[0.07,0.41]}\end{array}$ & $\begin{array}{c}0.54^{* * *} \\
{[0.37,0.71]}\end{array}$ & $\begin{array}{c}0.41^{* * *} \\
{[0.25,0.58]}\end{array}$ & $\begin{array}{c}0.61^{* * *} \\
{[0.44,0.78]}\end{array}$ & $\begin{array}{c}0.47^{* * *} \\
{[0.31,0.63]}\end{array}$ \\
\hline \multicolumn{7}{|l|}{ Year 15 Bullying: } \\
\hline Less than Weekly & & $\begin{array}{c}0.06 \\
{[-0.11,0.23]}\end{array}$ & & $\begin{array}{c}0.20^{*} \\
{[0.03,0.37]}\end{array}$ & & $\begin{array}{c}0.30^{* * *} \\
{[0.14,0.47]}\end{array}$ \\
\hline Weekly Bullying & & $\begin{array}{c}0.25^{* * *} \\
{[0.10,0.40]}\end{array}$ & & $\begin{array}{c}0.43^{* * *} \\
{[0.27,0.58]}\end{array}$ & & $\begin{array}{c}0.52^{* * *} \\
{[0.37,0.67]}\end{array}$ \\
\hline Daily Bullying & & $\begin{array}{c}0.78^{* * *} \\
{[0.47,1.09]}\end{array}$ & & $\begin{array}{c}1.07^{* \star *} \\
{[0.76,1.38]}\end{array}$ & & $\begin{array}{c}1.21^{* * *} \\
{[0.91,1.51]}\end{array}$ \\
\hline \multicolumn{7}{|l|}{ Year 9 Bullying: } \\
\hline Less than Weekly & & $\begin{array}{c}-0.02 \\
{[-0.15,0.11]}\end{array}$ & & $\begin{array}{c}0.08 \\
{[-0.05,0.21]}\end{array}$ & & $\begin{array}{c}-0.00 \\
{[-0.13,0.13]}\end{array}$ \\
\hline Weekly Bullying & & $\begin{array}{c}0.25^{\star * *} \\
{[0.12,0.38]}\end{array}$ & & $\begin{array}{c}0.14^{*} \\
{[0.01,0.27]}\end{array}$ & & $\begin{array}{c}0.15^{*} \\
{[0.02,0.28]}\end{array}$ \\
\hline Daily Bullying & & $\begin{array}{c}0.14 \\
{[-0.02,0.30]}\end{array}$ & & $\begin{array}{c}0.25^{\star \star} \\
{[0.10,0.41]}\end{array}$ & & $\begin{array}{c}0.09 \\
{[-0.07,0.24]}\end{array}$ \\
\hline$\frac{\text { Year 5: }}{\text { Teased A Lot }}$ & & $\begin{array}{c}0.21^{* * *} \\
{[0.07,0.34]}\end{array}$ & & $\begin{array}{c}0.13^{*} \\
{[0.02,0.24]}\end{array}$ & & $\begin{array}{c}0.08 \\
{[-0.05,0.21]}\end{array}$ \\
\hline Constant & $\begin{array}{c}0.15 \\
{[-0.06,0.36]}\end{array}$ & $\begin{array}{c}-0.03 \\
{[-0.24,0.19]}\end{array}$ & $\begin{array}{c}0.06 \\
{[-0.16,0.26]}\end{array}$ & $\begin{array}{c}-0.18 \\
{[-0.39,0.04]}\end{array}$ & $\begin{array}{c}0.11 \\
{[-0.10,0.32]}\end{array}$ & $\begin{array}{c}-0.10 \\
{[-0.32,0.11]}\end{array}$ \\
\hline
\end{tabular}

Note. ${ }^{* \star *} p<0.001,{ }^{* *} p<0.01,{ }^{*} p<0.05 .95 \%$ confidence intervals in brackets. Estimates produced by ordinary least squares regressions also controlling for sex at birth, race/ethnicity, parent nativity, mother's education and marital status at time of child's birth, child's age at Year 15 (mean centered), child's pubertal

development at Year 9 (mean centered), and whether, at Year 15, the child had a food allergy, a BMI qualifying them as obese, and/or a physical disability. 
SUPPLEMENTARY TABLE 3 Observed Results: Peer Victimization and Adolescent Mental Health, Levels and Disparities: Fragile Families \& Childhood Wellbeing Study, United States, 1998-2000 to 2014-2017

\begin{tabular}{|c|c|c|c|c|}
\hline & $\begin{array}{c}\text { Same-Sex } \\
\text { Attraction } \\
(\mathrm{N}=155), \\
\% \text { or mean }\end{array}$ & $\begin{array}{c}\text { Only Other-Sex } \\
\text { Attraction } \\
(\mathrm{N}=1,255), \\
\% \text { or mean }\end{array}$ & $\begin{array}{c}\text { Relative } \\
\text { Risk Ratio }\end{array}$ & $P$ \\
\hline \multicolumn{5}{|l|}{ Bullying Rates } \\
\hline \multicolumn{5}{|l|}{$\underline{\text { Parent Reports }}$} \\
\hline Year 5: Child gets teased a lot & 16.8 & 17.1 & 0.98 & 0.89 \\
\hline Year 9: Child gets teased a lot & $29.8^{* * *}$ & 19.9 & 1.50 & $<0.00$ \\
\hline \multicolumn{5}{|l|}{ Child Reports } \\
\hline \multicolumn{5}{|l|}{ Year 9: } \\
\hline Any Bullying & $70.7^{* *}$ & 61.1 & 1.16 & $<0.00$ \\
\hline Bullying At Least Weekly & $48.5^{\star * *}$ & 36.8 & 1.32 & $<0.00$ \\
\hline Daily Bullying & $24.1^{* * *}$ & 14.2 & 1.70 & $<0.00$ \\
\hline \multicolumn{5}{|l|}{ Year 15: } \\
\hline Any Bullying & $38.0^{* * *}$ & 23.6 & 1.61 & $<0.00$ \\
\hline Bullying At Least Weekly & $25.7^{* * *}$ & 14.0 & 1.84 & $<0.00$ \\
\hline Daily Bullying & $7.0^{* * *}$ & 2.2 & 3.18 & $<0.00$ \\
\hline \multicolumn{5}{|l|}{ Adolescent Mental Health } \\
\hline \multicolumn{5}{|l|}{ Parent Reports } \\
\hline Internalizing Scale [0 - 2] & $0.4^{* * *}$ & 0.2 & & $<0.00$ \\
\hline Diagnosed with Anxiety/Depression & $21.8^{* * *}$ & 9.8 & 2.22 & $<0.00$ \\
\hline Taking Anxiety/Depression Med & $8.6^{\star * \star}$ & 2.5 & 3.44 & $<0.00$ \\
\hline \multicolumn{5}{|l|}{ Teen Reports } \\
\hline Anxiety Scale [0 - 3] & $1.1^{* * *}$ & 0.8 & & $<0.00$ \\
\hline Depression Scale [0 - 3] & $0.8^{* \star *}$ & 0.6 & & $<0.00$ \\
\hline
\end{tabular}

Note. ${ }^{* * *} p<0.001,{ }^{* *} p<0.01,{ }^{*} p<0.05$. Scale ranges in brackets; higher values indicate increased symptomology. 